\title{
Primary tonsilar ALK negative anaplastic large cell lymphoma - report of a rare entity with brief review of literature
}

\author{
Archana Shetty, Vijaya C, Geethamani V \\ Department of pathology, Sapthagiri Institute of Medical Sciences and Research Center, Bangalore, India \\ Correspondence: Archana Shetty, MBBS, MD. Address: SIMS \& RC, street no.15, Hesaraghatta main road, \\ Chikkasandra, Bangalore 560090, India. E-mail: archanashetty2924@gmail.com
}

Received: February 25, 2014

Accepted: April 24, 2014

Online Published: April 28, 2014

DOI : $10.5430 /$ crcp.v1n2p59

URL: http://dx.doi.org/10.5430/crcp.v1n2p59

\begin{abstract}
Primary extra-nodal non-Hodgkin's lymphomas of the head and neck account for $10 \%-20 \%$ of all non-Hodgkin's lymphomas, with primary tonsillar lymphoma accounting for less than $1 \%$ of cases. The recent edition of WHO has included anaplastic large cell lymphoma (ALCL) ALK negative as a provisional entity. Studies and reports are still insufficient till date, to conclusively comment about the clinical behavior and prognosis of this rare entity. Also, the expression of ALK protein, which was documented to be a favorable prognostic indicator, has now been questioned as studies documenting no favorable outcome with ALK protein expression have been reported. We present a case of primary ALCL, ALK negative, of the tonsils, presenting as unilateral tonsillar enlargement, which is not only rare but also has a distinct clinical and immunohistochemical profile.
\end{abstract}

\section{Key words}

Anaplastic large cell lymphoma, ALK protein, PAX-5, Tonsils

\section{I ntroduction}

Lymphomas, which represent malignant lymphoproliferative diseases, are generally classified as Hodgkin's and nonHodgkin's lymphomas. Primary non-Hodgkin's lymphoma of the upper aero-digestive tract though common ${ }^{[1]}$, primary involvement of the tonsils in cases of ALK negative anaplastic large lymphoma, is rare. We present a case report ALK -ve anaplastic large cell lymphoma (ALCL), the prognosis and the treatment aspects of which are still in the grey zone.

\section{Case report}

A 38 year old male patient, presented to the ENT outpatient department with complaints of recurrent sore throat, for previous episodes the treatment having being taken from a local doctor. The patient was well nourished, with no complaints of loss of weight or appetite. His past medical and family history were unremarkable. Low grade fever was present, which according to the patient was noticed since 15 days. Oral examination revealed bilaterally enlarged, congested tonsils, more on the right. Routine blood and biochemical investigations were within normal limits, and the patient was taken up for tonsillectomy, with pre-operative work up, which was unremarkable. The dissected tonsils were 
sent for histopathological examination with a suspected clinical diagnosis of chronic tonsillitis. Gross examination showed right tonsils enlarged, measuring $4.5 \mathrm{~cm} \times 3 \mathrm{~cm} \times 2 \mathrm{~cm}$, with the cut section being homogenous grey white. Cut section of the left tonsil showed soft grey white to brown areas.

Figure 1. Cut section of the tonsils specimen, right sideenlarged right tonsil with a grey white homogenous appearance, left - normal left tonsil specimen

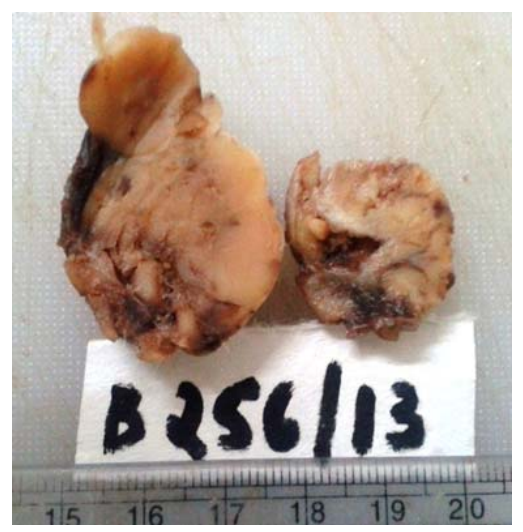

Microscopy of the right tonsil showed complete effacement of the tonsillar architecture, the entire tissue being replaced by a malignant tumour comprising of cells in sheets. A few individual cells had nuclear indentations, and some had prominent nucleoli. Mitotic activity was seen $(6-8 / 10$ hpf). The overlying epithelium was unremarkable (see Figure 2 A-D). The left tonsil showed features of chronic tonsillitis, which otherwise was unremarkable. With a provisional diagnosis of non-Hodgkin's lymphoma, immunohisochemistry was done, with the following surprising results. The neoplastic cells were strongly positive for $\mathrm{CD} 3, \mathrm{CD} 30$ and weakly positive for CD5. CD20, CD15, Pax5, EMA, ALK and cyclinD1 were negative. The reactive B cells were positive for CD20 and PAX 5. The Ki-67 index was around $90 \%$.

Figure 2A. Tonsillar tissue showing overlying stratified squamous epithelium, with complete effacement of architecture.

Figure 2B. Sheets of neoplastic cells, with no definitive arrangement.

Figure 2C. Individual tumour cells, (arrow) with a hallmark cell having horseshoe shaped nucleus and perinuclear eosinophilic region.

Figure 2D. Immunohistochemistry showing strong CD30 Positivity of the tumour cells

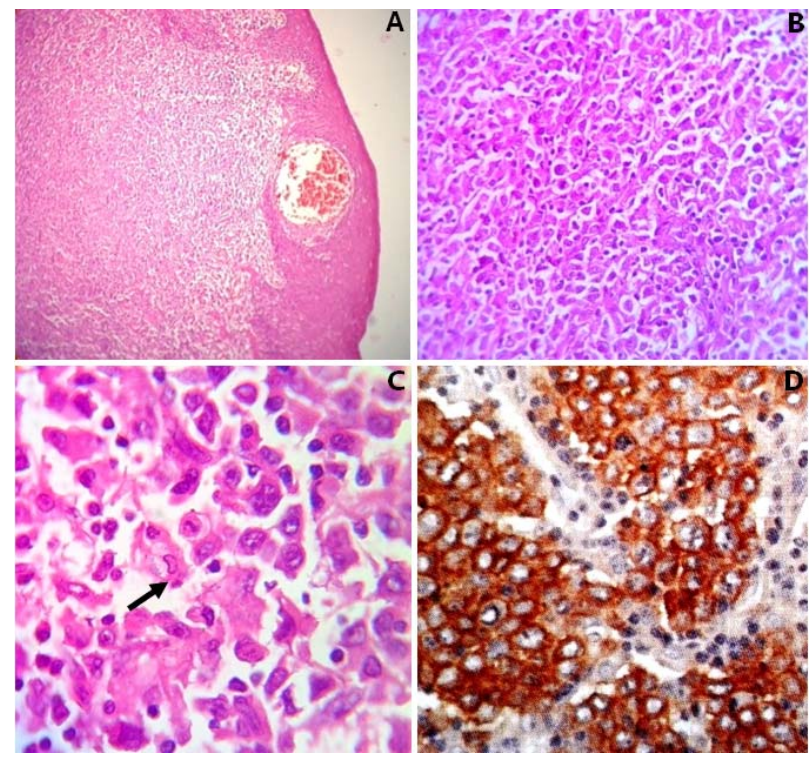

A final diagnosis of ALCL, ALK negative-tonsils was given. The patient was immediately referred to the oncology department, where a whole body imaging was done along with other relevant investigations to rule out any other primary tumour. The patient is doing well, till date 18 months post-surgery and is now on chemotherapy.

\section{Discussion}

Head and neck lymphomas represent one of the most common sites of extranodal lymphomas, second after the Gastrointestinal tract. Only about $2.5 \%$ of the lympohomas have a primary oral and peri-oral location, majority arising in 
the Waldeyer's ring which involves the palatine tonsils ${ }^{[2]}$. However, primary tonsillar lymphoma accounts for less than $1 \%$ of head and neck malignancies.

Primary tonsillar lymphomas occur predominantly in older males and present with B symptoms like fatigue, weight loss and fever. Oral examination often reveals unilaterally enlarged tonsils in majority of the cases. Our case was comparatively a younger patient with same presenting symptoms as above ${ }^{[2]}$. Although Fine needle aspiration cytology is a well-recognized diagnostic procedure for head and neck tumors; it always is challenging to distinguish between reactive and neoplastic lymphoid lesions relying only on the cytomorphology ${ }^{[3,4]}$. Further ancillary tests such as immunocytochemistry and/or PCR is often necessary, which, may not be available in health care centers specially in rural areas like ours.

Originally described by Stein et al. in 1985, ALCL, it has undergone a series of revisions which have led to a more refined and restrictive definition of the process. In particular two different entities are recognized, the ALK positive and the ALK negative based on genetic features ${ }^{[5,6]}$. The most frequent genetic alteration in the classical ALK positive ALCL is the translocation $\mathrm{t}(2 ; 5) \mathrm{p} 23 ; \mathrm{q} 35$, between the ALK gene on chromosome 2 and the nucleophosmin (NPM) gene on chromosome 5, leading to the nuclear/cytoplasmic positivity for the protein, which is not seen in ALK negative cases. The peak incidence of ALK negative ALCL in the recent edition of WHO is $40-65$ years with a male preponderance, as in the case presented. ALK positive cases occur more commonly in children and young adults ${ }^{[7,8]}$.

There are three groups of ALCL according to molecular and clinical criteria: primary systemic ALK positive anaplastic lymphoma, primary systemic ALK negative ALCL and primary cutaneous anaplastic lymphoma ${ }^{[9]}$. Although ALK negative ALCL is included by the WHO as a provisional entity; recent studies on this entity have documented differences in prognosis and management as compared to ALK positive ALCL ${ }^{[5]}$. The ALK expression in tonsillar ALCL's show a predilection for younger patients and has been attributed to a significantly better clinical outcome as stated in the studies by Berge et $a{ }^{[7]}$. Interestingly it has also been shown that ALK has immunogenic properties, thus causing the production of antibodies that can be easily detected in the serum and might be the reason for a relatively better prognosis ${ }^{[6]}$.

Histologically, ALCL both ALK positive and negative is characterized by a variable proportion of hallmark cells with horseshoe or kidney shaped nuclei often with an eosinophilic region near the nucleus. ALCL is not sustained by a unique histotype but actually includes five morphologic variants (common, giant cell rich, lympho-histiocytic small cell type and Hodgkin's type. The neoplastic cells in ALCL, ALK -ve, show a similar morphological spectrum to ALCL ALK +ve cases, although a small cell variant is not recognized ${ }^{[8]}$.

Immunohistochemically the neoplastic cells express CD30, more than half cases express one or more $\mathrm{T}$ cell markers $\mathrm{CD} 4$, CD 2 and CD3 more often than CD5.A majority of them also stain for EMA ${ }^{[4,6,10]}$. However in cases which lack T cell markers can often be confused with Hodgkin's lymphomas. PAX 5, the marker used for confirming the B- lineage, may be useful in such cases, as classical Hodgkin's shows weak positivity and ALCL is always negative for the same ${ }^{[8,11]}$. Feldman et al. have reported three cases of ALCL's with PAX5 positivity, this positivity being attributed to the extra copies of the PAX gene ${ }^{[12]}$. Also the search for Epstein Barr virus (EBV) is negative in most, if not all ALCL'S both by in situ hybridization and by immunohistochemistry; such negativity is regarded as one of the distinguishing features between ALCL and HL in controversial cases ${ }^{[6,12]}$. Another entity, the diffuse large B cell lymphoma, which is the commonest NHL in the tonsils, can be ruled out as it is positive for plasma cell markers (CD138) and immunoglobulin light chain ${ }^{[13]}$. Thus a combination of markers ruling out the closest differentials, as was done in our case is necessary for a final diagnosis: ALK negative ALCL; ALK positive ALCL; Peripheral T cell lymphoma (NOS); ALK positive DLBC; Poorly differentiated SCC; Hodgkin's lymphoma.

Finally, it is important to distinguish ALK negative cases of ALCL as they often run a protracted course, unlike ALK positive cases. $70 \%-80 \%$ of ALK positive ALCL's attain remission after adopting anthracyclin containing regimens, by contrast only $30 \%-50 \%$ of ALK negative cases obtain stable remission after the same regimens ${ }^{[6]}$. Wang et al. in their 
study showed that three factors: advanced stage, lack of expression of ALK and high Ki-67 expression, were associated with treatment failure ${ }^{[14]}$. Combined chemo radiation has been used as the primary treatment for localized aggressive non-Hodgkin's lymphoma ${ }^{[7]}$. However, a definite recommendation for treatment of primary ALK negative tonsillar lymphoma is difficult to make as larger studies are needed to throw light on the same ${ }^{[15]}$.

\section{Conclusion}

Primary tonsillar non Hodgkins lymphoma is rare with ALCL, with ALK negativity being even rarer. A careful study of the histomorphological features along with a panel of selective markers is often needed for a definitive diagnosis. The prognosis and treatment of ALK negative cases still remains controversial, with larger case series needed for a definitive conclusion.

\section{References}

[1] Chua SC, Rozalli FI, O'Connor SR. Imaging features of primary extranodal lymphomas. Clin Radiol. 2009 Jun; 64(6): 574-88. http://dx.doi.org/10.1016/j.crad.2008.11.001

[2] D Salplahta, Maria Victoria Comănescu, F Anghelina, Elena Ioniță, Carmen Aurelia Mogoantă, Liliana Anghelina. Non-Hodgkin lymphomas of Waldeyer's ring Rom J Morphol Embryol. 2012; 53(4): 1057-1060. PMid: 23303032.

[3] Daskalopoulou D, Papanastasiou C, Markidou S, Rapidis AD. The diagnostic value of fine needle aspiration cytology in Waldeyer's ringlymphomasOral Oncol. 2001 Jan; 37(1): 36-41.

[4] Hudacko R, Rapkiewicz A, Berman RS, Simsir A. ALK-negative anaplastic large cell lymphoma mimicking a soft tissue sarcoma. J Cytol. 2011 Oct; 28(4): 230-3. http://dx.doi.org/10.4103/0970-9371.86362

[5] Tilly H, Gaulard P, Lepage E, Dumontet C, Diebold J, Plantier I, et al. Primary anaplastic large-cell lymphoma in adults: clinical presentation, immunophenotype, andoutcome. Blood. 1997 Nov 1; 90(9): 3727-34. PMid: 9345059.

[6] Pier Paolo Piccaluga, Anna Gazzola, Claudia Mannu, Claudio Agostinelli, Francesco Bacci, Elena Sabattini, et al. Pathobiology of Anaplastic Large Cell LymphomaAdv Hematol. 2010; 2010: 345053.

[7] Ten Berge RL, Oudejans JJ, Ossenkoppele GJ, Pulford K, Willemze R, Falini B, et al. ALK expression in extranodal anaplastic large cell lymphoma favours systemic disease with (primary) nodal involvement and a good prognosis and occurs before disseminationJ Clin Pathol. 2000 Jun; 53(6): 445-50.

[8] Swerdlow S, Campo E, Harris N, et al (eds). WHO classification of tumours of haematopoietic and lymphoid tissues. In: Bosman F, Jaffe E, Lakhani S, Ohgaki H (eds), World Health Organization Classification of Tumours, 4th edn. International Agency for Research on Cancer: Lyon. 2008.

[9] Taniai H, Furusyo N, Murata M, Mitsumoto F, Shimizu M, Toyoda K, et al. A case report of human immunodeficiency virus-associated anaplastic lymphoma kinase protein-negative anaplastic large cell lymphoma. Springerplus. 2013 Aug 23; 2: 400. http://dx.doi.org/10.1186/2193-1801-2-400

[10] Grandhi A, Boros AL, Berardo N, Reich RF, Freedman PD. Two cases of CD30+, anaplastic lymphoma kinase (ALK) negative anaplastic large celllymphoma with oral manifestations. Oral Surg Oral Med Oral Pathol Oral Radiol. 2013 Feb; 115(2): e41-7. http://dx.doi.org/10.1016/j.oooo.2012.04.010

[11] Tamaru J, Tokuhira M, Nittsu N, Nakamura S, Ichinohasama R, Suzuki R, et al. Mikata AHodgkin-like anaplastic large cell lymphoma (previously designated in the REAL classification) has same immunophenotypic features to classical Hodgkin lymphoma. Leuk Lymphoma. 2007 Jun; 48(6): 1127-38. PMid: 17577776. http://dx.doi.org/10.1080/10428190701342000

[12] Feldman AL, Law ME, Inwards DJ, Dogan A, McClure RF, Macon WR. PAX5-positive T-cell anaplastic large cell lymphomas associated with extra copies of the PAX5 gene locusMod Pathol. 2010 Apr; 23(4): 593-602. http://dx.doi.org/10.1038/modpathol.2010.4

[13] Reichard KK, McKenna RW, Kroft SH. ALK-positive diffuse large B-cell lymphoma: report of four cases and review of the literature Mod Pathol. 2007 Mar; 20(3): 310-9. PMid: 17277765. http://dx.doi.org/10.1038/modpathol.3800742

[14] Wang YF, Yang YL, Gao ZF, Zhou CJ, Gregg X, Shi YF, et al. Clinical and laboratory characteristics of systemic anaplastic large cell lymphoma in Chinese patients. J Hematol Oncol. 2012 Jul; 7(5): 38. http://dx.doi.org/10.1186/1756-8722-5-38

[15] Mohammadianpanah M, Omidvai S, Mosalei A, Ahmadloo N. Treatment results of tonsillar lymphoma: a 10-year experience. Ann Hematol. 2005 Apr; 84(4): 223-6. PMid: 15042316. http://dx.doi.org/10.1007/s00277-004-0860-0 